\title{
Comparison of airway reactivity induced by histamine, methacholine, and isocapnic hyperventilation in normal and asthmatic subjects
}

\author{
ALAN T AQUILINA \\ From the Pulmonary Division, Department of Medicine, State University of New York at Buffalo, \\ New York, USA
}

ABSTRACT In an investigation of a rapid screening test for airway reactivity using isocapnic hyperventilation with room air and cold air the results of this test were compared with the airway response to histamine and methacholine challenge. Twelve non-atopic, non-smoking normal subjects and 11 subjects with stable asthma who had an $\mathrm{FEV}$ above $74 \%$ of the predicted value were studied. In the normal subjects isocapnic hyperventilation with room air $\left(75 \mathrm{l} / \mathrm{min} ; 22^{\circ} \mathrm{C}\right.$ $\left(\mathrm{SEM} 0.2^{\circ}\right) ; 10 \mathrm{mg} \mathrm{H}_{2} \mathrm{O} / \mathrm{l}$ air $)$ and isocapnic hyperventilation with cold air $\left(77 \mathrm{l} / \mathrm{min} ;-10^{\circ} \mathrm{C}\left(0 \cdot 9^{\circ}\right)\right.$; $2.4 \mathrm{mg} \mathrm{HO} / 1$ air) produced no significant change in $\mathrm{FEV}$. In the asthmatic subjects, hyperventilation with room air $\left(71 \mathrm{l} / \mathrm{min} ; 22^{\circ} \mathrm{C}\left(0.8^{\circ}\right) ; 10 \mathrm{mg} \mathrm{H} \mathrm{O} / \mathrm{l}\right.$ air $)$ caused a mean fall in $\mathrm{FEV}$ of $11.7 \%$; cold air hyperventilation $\left(70 \mathrm{l} / \mathrm{min} ;-10^{\circ} \mathrm{C}\left(0.9^{\circ}\right) ; 2.4^{2} \mathrm{mg} \mathrm{H} \mathrm{O} / \mathrm{l}\right.$ air $)$ caused a mean fall in $\mathrm{FEV}_{1}$ of $20.4 \%$. Cold air hyperventilation produced greater separation between normal and asthmatic subjects than room air. The provocative concentration of histamine required to reduce the FEV by $20 \%\left(\mathrm{PC}_{20}\right)$ correlated closely with the $\mathrm{PC}_{20}$ for methacholine $(\mathrm{r}=0.95 ; \mathrm{p}<0.001)$. Both tests separated normal from asthmatic subjects. $\mathrm{PC}_{20}$ for both histamine and methacholine correlated with the fall in FEV after cold air hyperventilation $(r=0.93, p<0.001 ; r=0.87, p<$ 0.001 respectively). We conclude that the results of a rapid screening test based on hyperventilation with cold air correlate well with a standard pharmacological challenge.

Bronchial airway hyperreactivity to a variety of stimuli is a characteristic feature of asthma. ${ }^{1}$ Bronchial inhalation challenges are therefore used as laboratory tests for the diagnosis and assessment of patients with asthma, for the study of risk factors in lung disease, and for the study of occupational airway disease..$^{2-5}$ The most widely used methods of provocation have been exercise and inhalation of pharmacological agents such as histamine and methacholine, though exercise challenge may be a less sensitive test of airway reactivity. ${ }^{6}$ Pharmacological challenge tests have been widely studied. ${ }^{23}$ The results are influenced by a variety of technical factors that require standardisation. ${ }^{7}$ In addition, the tests are time consuming, often requiring an hour or

This paper was presented in part at the annual meeting of the American Thoracic Society, Los Angeles, California, in May 1982.

Address for reprint requests: Dr Alan T Aquilina, Pulmonary Division, Erie County Medical Center, 462 Grider Street, Buffalo, New York 14215, USA.

Accepted 7 June 1983 more. Recently isocapnic hyperventilation has been used and advocated as a simple test for non-specific airway hyperreactivity. ${ }^{8} \mathrm{~A}$ simple, rapid screening test would be advantageous for diagnostic and epidemiological studies. ${ }^{9} 10$

In this study we developed a rapid screening test for non-specific airway reactivity using isocapnic $\stackrel{9}{\triangle}$ hyperventilation with room air and cold air. The $\frac{D}{0}$ results were then compared with the airway responses to inhaled histamine and methacholine.

\section{Methods}

SUBJECTS

Twelve untrained, non-smoking, non-atopic normal $\stackrel{\bullet}{\complement}$

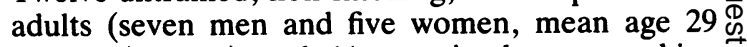
(SEM 4) years) and 11 untrained, non-smoking stable asthmatic adults (three men and eight women, $\frac{0}{\circ}$ mean age 25 (6) years) participated in this study. The $\overrightarrow{\mathbb{D}}$ asthmatic subjects were chosen on the basis of clinical $\frac{\mathcal{P}}{\mathbb{D}}$ stability and mild symptoms. They all had a history of $\propto$ 
episodic dyspnoea and wheezing consistent with asthma as defined by the American Thoracic Society. ${ }^{1}$

Five of the asthmatic subjects had been free of symptoms for more than six months and required no medications. Six asthmatic subjects used oral theophylline or inhaled bronchodilators. No one required inhaled or oral steroid treatment.

At the time of the study all subjects had been free of symptoms of any respiratory illness for eight weeks. Symptoms of asthma were all well controlled, with no exacerbations during the previous eight weeks. All medication was withheld for 24 hours before testing. Informed written consent was obtained from each subject.

\section{LUNG FUNCTION MEASUREMENT}

Airway resistance and lung volumes were measured in a variable pressure constant volume plethysmograph (Warren Collins Inc) and displayed on a Tektronix storage oscilloscope. Airway resistance was measured, corrected for lung volume, and expressed as its reciprocal specific airway conductance (sGaw). ${ }^{11}{ }^{12}$ Measurements were made in triplicate and the mean values determined. The subject then performed maximum forced vital capacities in triplicate. A Fleisch \#7322 pneumotachograph measured flow at the mouth; this was integrated to produce a volume signal, which was displayed on a Hewlett-Packard X-Y recorder. FEV, was determined by spirometry. ${ }^{13}$

\section{HYPERVENTILATION TEST}

Cold air was generated by a heat exchanger. The subject inspired room air through copper tubing, 120 $\mathrm{cm}$ long and $6 \mathrm{~cm}$ wide, which was cooled externally by circulating ethylene glycol maintained at $-30^{\circ} \mathrm{C}$. A one way Hans Rudolph valve was placed on the inspiratory port. The inspired air temperature (Ti) was measured by a thermometer $4 \mathrm{~cm}$ upstream from the mouth. The water content of room and inspired air was calculated from the temperature and relative humidity of room air, measured by a standard mercury thermometer and hydroscopic membrane hygrometer and from measurements of inspired air temperature. Relative humidity was expressed as $\mathrm{mg}$ $\mathrm{H}_{2} \mathrm{O}$ per litre of air. ${ }^{14}$ Expired air was directed into a 7 litre reservoir bag that was constantly evacuated through a calibrated rotameter by a vacuum pump. End tidal carbon dioxide $\left(\mathrm{P}_{\mathrm{ET}} \mathrm{CO}_{2}\right)$ was measured at the mouth by a Beckman LB-2 analyser; carbon dioxide $(50 \%)$ was added to the inspired air to maintain a constant $\mathrm{P}_{\mathrm{ET}} \mathrm{CO}_{2}$ during hyperventilation.

Subjects were seated and inspired room air or cold air through the heat exchanger. The target minute ventilation ( $\dot{V E}_{\mathrm{E}}$ ) chosen for each subject was $70 \%$ of the calculated indirect maximum breathing capacity. ${ }^{15}$ Target VE was maintained by instructing the subject to breath enough to keep the reservoir bag filled. Each period of hyperventilation lasted three minutes. sGaw, lung volumes, and spirometric values were determined before and five minutes after cessation of hyperventilation.

\section{INHALATION TESTS}

Test aerosols of histamine or methacholine were generated from a DeVilbiss \#45 nebuliser operated by compressed air at $50 \mathrm{lb} / \mathrm{in}^{2}(0 \cdot 345 \mathrm{kPa})$ and a flow rate of $51 / \mathrm{min}$ to give an output of $0.156 \mathrm{ml} / \mathrm{min}$. A nose clip was worn and the aerosol inhaled through the mouth by five slow vital capacity manoeuvres, each separated by a five second breath hold. A buffered saline diluent was nebulised first, followed at five minute intervals by twofold increasing concentration of either histamine or methacholine $(0 \cdot 03-25$ $\mathrm{mg} / \mathrm{ml}$ ). sGaw, lung volumes, and spirometric values were determined before and five minutes after each dose. Inhalations were discontinued when the FEV had fallen by $20 \%$ or more. The provocative concentrations of histamine and of methacholine producing a $20 \%$ fall in $\mathrm{FEV}_{1}\left(\mathrm{PC}_{20} \mathrm{H}\right.$ and $\left.\mathrm{PC}_{20} \mathrm{M}\right)$ were obtained from log dose response curves by linear interpolation.

\section{PROTOCOL}

Each subject presented to the laboratory at the same time of day for four days over a two week period. The subjects rested for 30 minutes before testing. The four tests-one inhalation test with histamine and one with methacholine, isocapnic hyperventilation with room air, and hyperventilation with cold air were performed in a random order on the four days.

All asthmatic subjects received the inhaled $\beta$ agonist metaproterenol at the completion of each protocol. After completion of the study each subject was asked about any side effect.

\section{ANALYSIS OF RESULTS}

Linear regression analysis was used to determine the relation between $\mathrm{PC}_{20} \mathrm{M}, \mathrm{PC}_{20} \mathrm{H}$, and the fall in $\mathrm{FEV}$, after isocapnic hyperventilation inhaling room air and cold air. Student's $t$ tests for paired and unpaired observations were used to evaluate significance. ${ }^{16}$

\section{Results}

The results of the challenge tests for the asthmatic subjects are summarised in table 1 . The asthmatic subjects had a mean baseline FEV above $74 \%$ of the predicted mean value (mean 91\% (SD 16\%)). Normal subjects had a mean FEV, of 3.401 ( $93 \%$ (11\%) predicted). In the normal subjects the mean 
Table 1 Results of inhalation challenge in asthmatic subjects

\begin{tabular}{|c|c|c|c|c|c|}
\hline \multirow{2}{*}{$\begin{array}{l}\text { Subject } \\
\text { No }\end{array}$} & \multirow{2}{*}{$\begin{array}{l}\text { Baseline } \\
F E V, \\
(l(\% \text { pred }))\end{array}$} & \multirow{2}{*}{$\begin{array}{l}P C_{2} H \\
(m g l m l)\end{array}$} & \multirow{2}{*}{$\begin{array}{l}P C_{2} M \\
(m g / m l)\end{array}$} & \multicolumn{2}{|c|}{ Fall in $F E V_{1}$ after } \\
\hline & & & & $\begin{array}{l}\text { IHRA } \\
(\%)\end{array}$ & $\begin{array}{l}I H C A \\
(\%)\end{array}$ \\
\hline $\begin{array}{r}1 \\
2 \\
3 \\
4 \\
5 \\
6 \\
7 \\
8 \\
9 \\
10 \\
11\end{array}$ & $\begin{array}{l}2 \cdot 57(77) \\
3 \cdot 18(83) \\
3 \cdot 86(120) \\
3 \cdot 58(84) \\
2 \cdot 26(77) \\
2 \cdot 65(76) \\
2 \cdot 96(100) \\
2 \cdot 75(74) \\
2 \cdot 85(90) \\
3 \cdot 35(113) \\
3 \cdot 25(110)\end{array}$ & $\begin{array}{l}0.13 \\
0.45 \\
0.50 \\
0.21 \\
0.84 \\
0.65 \\
2.3 \\
1.7 \\
5.1 \\
4.0 \\
7.9\end{array}$ & $\begin{array}{l}0 \cdot 14 \\
0 \cdot 40 \\
0 \cdot 49 \\
0 \cdot 21 \\
0 \cdot 36 \\
0.70 \\
1.7 \\
1.8 \\
3 \cdot 2 \\
3 \cdot 5 \\
19\end{array}$ & $\begin{array}{c}22 \\
22 \\
20 \\
12 \\
15 \\
14 \\
7 \cdot 6 \\
4 \cdot 6 \\
3 \cdot 6 \\
5 \cdot 5 \\
3 \cdot 1\end{array}$ & $\begin{array}{l}37 \\
38 \\
30 \\
28 \\
23 \\
19 \\
12 \cdot 1 \\
11 \\
9 \cdot 1 \\
8 \cdot 6 \\
8 \cdot 0\end{array}$ \\
\hline Mean & $3.02(91)$ & $2 \cdot 16$ & $2 \cdot 86$ & $11 \cdot 7$ & $20 \cdot 4$ \\
\hline
\end{tabular}

$\%$ pred-percentage of mean predicted $\mathrm{FEV}_{1} ; \mathrm{PC}_{20} \mathrm{H}, \mathrm{PC}_{20} \mathrm{M}-$ concentrations of histamine and methacholine required to reduce the FEV by $20 \%$; IHRA - isocapnic hyperventilation with room air: IHCA - isocapnic hyperventilation with cold air.

fall in sGaw after isocapnic hyperventilation of room air and cold air was $-2.5 \%$ (range $+10 \%$ to $-11 \%$ ) and $-4.2 \%$ (range $+10 \%$ to $-13 \%$ ) respectively ( $\mathrm{p}$ $>0.01)$. There was no significant change in FEV after either stimulus (table 2 and fig 3 ). All asthmatic subjects responded to each of the provocative challenges with a fall in FEV, (table 1). After hyperventilation of room air there was a mean fall in sGaw of $40 \%$ (range $14 \%$ to $74 \%$ ) and a mean fall in FEV, of $11.7 \%$ (tables 1 and 2 and fig 1). After hyperventilation of cold air asthmatic subjects had a mean fall in sGaw of $52 \%$ (range $26 \%$ to $86 \%$ ) and a mean fall in FEV of $20.4 \%$ (tables 1 and 2). Thus isocapnic hyperventilation separated normal from asthmatic subjects with room air $(p<0.001)$, but less so than with cold air $(\mathrm{p}<0.001 ;$ fig 1$)$.

Both methacholine and histamine inhalation tests separated normal from asthmatic subjects $(p<0 \cdot 01$; fig 2). The $\mathrm{PC}_{2,0} \mathrm{M}$ correlated closely with the $\mathrm{PC}_{20} \mathrm{H}(\mathrm{r}$ $=0.95, \mathrm{p}<0.001$; fig 3 ).

Bronchial responsiveness to cold air correlated with responsiveness to both methacholine and hista-

Table 2 Results of isocapnic hyperventilation

\begin{tabular}{|c|c|c|c|c|}
\hline & $\begin{array}{l}\dot{V}_{E} \\
(l / \text { min })\end{array}$ & $\begin{array}{l}\text { Mean (SEM) } \\
T i \\
\left({ }^{\circ} \mathrm{C}\right)\end{array}$ & $\begin{array}{l}\mathrm{H}_{2} \mathrm{O} \text { content } \\
\mathrm{mg} / \mathrm{l} \text { air }\end{array}$ & $\begin{array}{l}\% \text { fall } \\
\text { FEV }\end{array}$ \\
\hline $\begin{array}{l}\text { Room air } \\
\text { Normal } \\
\text { Asthmatic }\end{array}$ & $\begin{array}{l}75 \\
71\end{array}$ & $\begin{array}{l}22(0 \cdot 2) \\
22(0 \cdot 8)\end{array}$ & $\begin{array}{l}10 \\
10\end{array}$ & $\begin{array}{l}0 \\
11.7\end{array}$ \\
\hline $\begin{array}{l}\text { Cold air } \\
\text { Normal } \\
\text { Asthmatic }\end{array}$ & $\begin{array}{l}77 \\
70\end{array}$ & $\begin{array}{l}-10(0.9) \\
-10(0.9)\end{array}$ & $\begin{array}{l}2 \cdot 4 \\
2 \cdot 4\end{array}$ & $\begin{array}{l}0 \\
20 \cdot 4\end{array}$ \\
\hline
\end{tabular}

$\dot{\mathrm{V}}_{\mathrm{E}-\text { mean minute ventilation; } \mathrm{Ti}-\text { mean temperature of inspired }}$ air: \% fall FEV - mean percentage fall in $\mathrm{FEV}_{1}$ after isocaipnic hyperventilation.

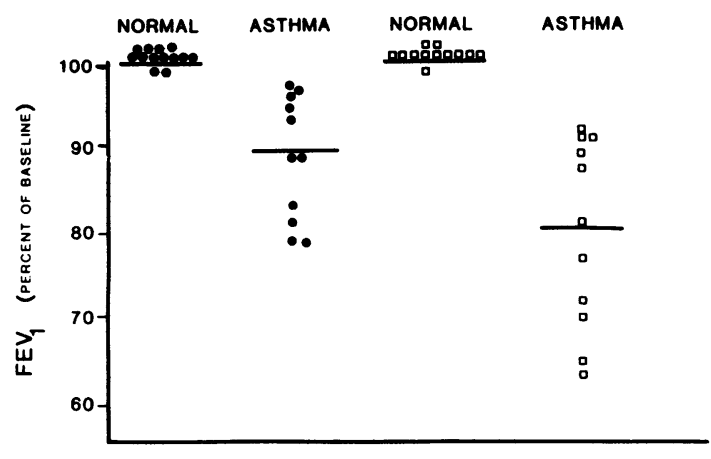

Fig 1 Individual values of the fall in $F E V$, as percentages of baseline $F E V$, in normal and asthmatic subjects in response to isocapnic hyperventilation of room air $(O)$ and cold air ( $\square$ ). Horizontal bars indicate arithmetic mean.

mine (table 1 and figs 4 and 5). There was a close linear relation between the fall in $\mathrm{FEV}_{1}$ after $O$ isocapnic hyperventilation of cold air and both $\mathrm{PC}_{20} \mathrm{H}$ $(\mathrm{r}=0.93, \mathrm{p}<0.001)$ and $\mathrm{PC}_{20} \mathrm{M}(\mathrm{r}=0.87, \mathrm{p}<0.001)$. Both $\mathrm{PC}_{20} \mathrm{H}$ and $\mathrm{PC}_{20} \mathrm{M}$ correlated with the fall in $\mathrm{FEV}$, after hyperventilation of room air $(\mathrm{r}=0.90$ and $0 \cdot 84)$.

\section{Discussion}

This study shows that the airway response to a rapid 10 minute challenge with isocapnic hyperventilation $\propto$ of cold air correlates well with the results of standard $\overrightarrow{\vec{O}}$ methacholine and histamine challenge tests. Our 3 results confirm the findings of Deal and coworkers, ${ }^{8} \supset$ who observed a response to cold air in patients with current asthma compared with normal subjects. $\mathrm{O}^{\prime} B y r n e$ and associates ${ }^{17}$ also found a linear relationship between the PC $_{20} \mathbf{M}$ and PD $_{10}$ RHE (respiratory heat exchange required to reduce the $\mathrm{FEV}_{1} 10 \%$ ).

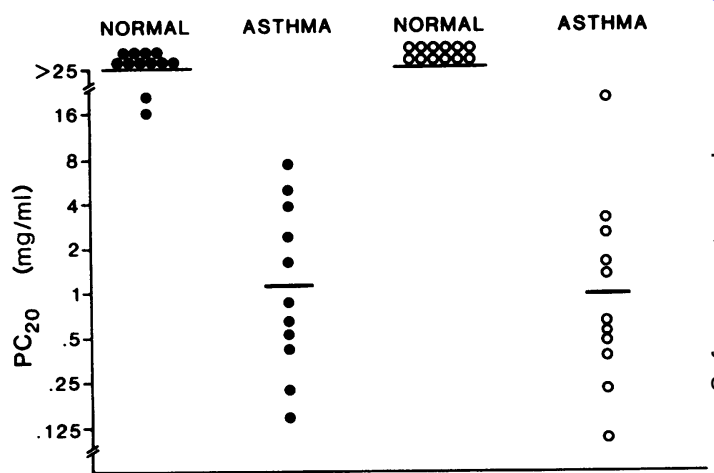

Fig 2 Individual values of the provocative doses of histamine $(O)$ and methacholine $(O)$ reducing the FEV by $20 \%\left(P C_{20}\right)$ in normal and asthmatic subjects. Horizontal bars indicate geometric mean: 


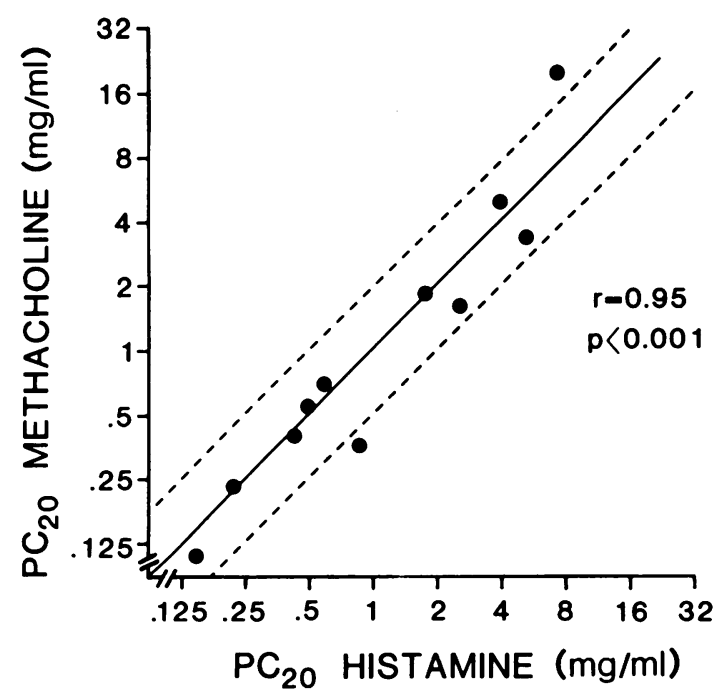

Fig 3 Comparison of $\mathrm{PC}_{20}$ for histamine and for methacholine in asthmatic subjects; dashed line indicates a twofold concentration difference; the solid line is the line of identity.

Furthermore, they observed that the cold air responsiveness was highly reproducible.

Isocapnic hyperventilation of cold air has been advocated as a simple test of non-specific airway reactivity. ${ }^{818}$ The protocol is simple to perform and rapid (10 minutes) and the training period for the subjects is negligible. The equipment is available in most hospitals and pulmonary function laboratories and can be compact and mobile. ${ }^{5}$ All the variables ( $\dot{\mathrm{VE}}, \mathrm{P}_{\mathrm{ET}} \mathrm{CO}_{2}$, inspired air temperature, and humidity) can be satisfactorily controlled. The procedure was well tolerated by all subjects, whereas four normal and three asthmatic subjects had side effects from histamine (flushing, headache, hoarseness, laryngospasm) and methacholine (increased watery

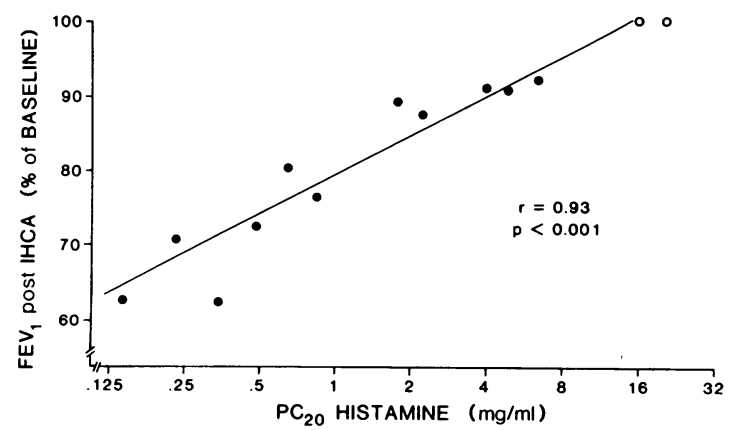

Fig 4 Comparison of $P C_{20}$ for histamine and fall in FEV, with isocapnic hyperventilation with cold air (IHCA)

(expressed as percentage of baseline). Closed circles indicate asthmatic and open circles normal subjects.

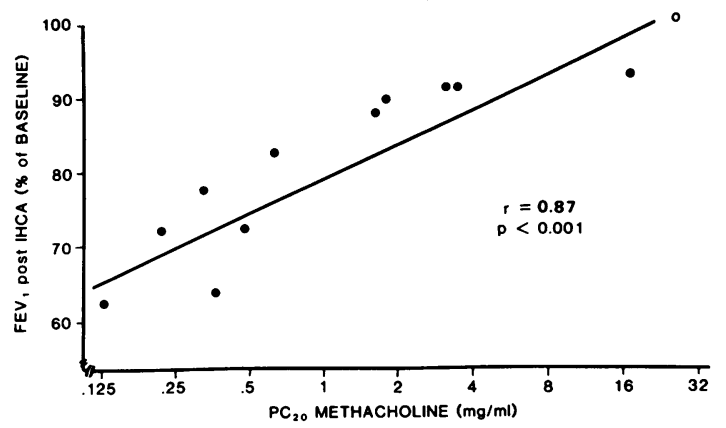

Fig 5 Comparison of $P C_{20}$ for methacholine and fall in $F E V$, with isocapnic hyperventilation with cold air (IHCA) (expressed as percentage of baseline value). Closed circles indicate asthmatic subjects and the open circle a normal subject.

secretion). Dryness of the mouth was the major subjective symptom after isocapnic hyperventilation of cold air. Bronchoconstriction was readily reversed by inhaled metaproterenol.

The sensitivity of the isocapnic hyperventilation of cold air test is good. Our data and those of Deal et al and O'Byrne et $a l^{17}$ have showed that the test will induce a significant response in patients with mild asthma. Deal and his coworkers ${ }^{8}$ demonstrated a response in all their asthmatic subjects, though in six patients the decrease in $\mathrm{FEV}_{1}$ was only $5-10 \%$. O'Byrne and others ${ }^{17}$ reported a response to isocapnic hyperventilation of cold air in 23 of 26 asthmatic subjects. The three non-responders had been symptom free for more than one year, and they had a normal $\mathrm{PC}_{20} \mathrm{M}$, above $25 \mathrm{mg} / \mathrm{ml}$. Two normal subjects responded to both isocapnic hyperventilation of cold air and methacholine. Most normal non-atopic, non-smoking subjects, however, have a minimal response to isocapnic hyperventilation of cold air.

Recently Chatham and coworkers ${ }^{19}$ described a rapid methacholine inhalation challenge which gives responses that correlate well with those of the standard methacholine protocol. Normal people, however, show a wide range of sensitivity to histamine and methacholine, their responses often overlapping those of patients with asthma. ${ }^{6}{ }^{19}{ }^{20}$ The airway response in normal subjects challenged with isocapnic hyperventilation of cold air is usually minimal unless conditions are extreme. ${ }^{21}$ Thus care is needed in interpretating the results of the various bronchial challenge tests. ${ }^{322}$ There is often difficulty in defining the cut-off level between normal and asthmatic subjects and those with an atopic history. Previous studies suggest that there is a continuous distribution of response of non-specific airway reactivity in the population. ${ }^{8} 1720$ 
There are now two rapid screening tests for nonspecific airway reactivity. Isocapnic hyperventilation of cold air has recently been used in an occupational study.$^{23}$ Further study is necessary to define the sensitivity and specificity of these tests as well as their acceptability in occupational and population studies. ${ }^{23}$

\section{References}

${ }^{1}$ American Thoracic Society. Definitions and classifications of chronic bronchitis, asthma and pulmonary edema. Am Rev Respir Dis 1962;85:762-8.

2 Juniper EF, Frith PA, Hargreave FE. Airway responsiveness to histamine and methacholine: relationship to minimum treatment to control symptoms of asthma. Thorax 1981;36:575-9.

${ }^{3}$ Hargreave FE, Ryan G, Thomson NC; et al. Bronchial responsiveness to histamine or methacholine in asthma: measurement and clinical significance. $J$ Allergy Clin Immunol 1981;68:347-55.

${ }^{4}$ Boushey HA, Holtzman MJ, Sheller JR, Nadel JA. State of the art: bronchial hyperreactivity. Am Rev Respir Dis 1980;121:389-413.

${ }^{5}$ Brooks SM. The evaluation of occupational airways disease in the laboratory and workplace. J Allergy Clin Immunol 1982;70:56-66.

${ }^{6}$ Chathman M, Bleeker ER, Smith PL, Rosenthal RR, Mason P, Norman PS. A comparison of histamine, methacholine, and exercise airway reactivity in normals and asthmatics. Am Rev Respir Dis 1982;126:235-40.

${ }^{7}$ Ryan G, Dolovich MB, Obminski G, et al. Standardization of inhalation provocative tests: influence of nebulizer output, particle size and method of inhalation. J Allergy Clin Immunol 1981;66:156-64.

${ }^{8}$ Deal EC jun, McFadden ER jun, Ingram RH jun, Breslin FJ, Jaeger JJ. Airway responsiveness to cold air and hyperpnea in normal subjects and in those with hayfever and asthma. Am Rev Respir Dis 1980;121:621-8.

${ }^{9}$ McFadden ER Jr, Kiser R, deGroot WJ. Acute bronchial asthma: relationship between clinical and physiologic manifestations. N Engl J Med 1973;288:221-5.
I" Corrao WM, Braman SS, Irwin RS. Chronic cough as the sole presenting manifestation of bronchial asthma. $N$ Engl J Med 1979;300:633-7.

"DuBois AB, Botelho SY, Bedell GN, Marshall R, Comroe JH jun. A rapid plethysmographic method for measuring thoracic gas volume: a comparison with a nitrogen washout method for measuring functional residual capacity in normal subjects. $J$ Clin Invest 1956;35:322-6.

12 DuBois AB, Botelho SY, Comroe JH Jr. A new method for measuring airway resistance in man using a body plethysmograph: values in normal subjects and in patients with respiratory disease. $J$ Clin Invest 1956;35:327-35.

${ }^{13}$ Gardner RM. ATS Statement. Snowbird workshop on standardization of spirometry. Am Rev Respir Dis 1979;119:831-8.

${ }^{1+}$ Weast RC. Handbook of chemistry and physics. 59th ed Cleveland: Chemical Rubber Co, 1978:E-41. flow rate as a measure of ventilation capacity. $B r$ Med J 1959;ii:1041-7.

${ }^{16}$ Snedecor GW, Cochran WG. Statistical methods. 6th ed Ames, Iowa: Iowa State University Press, 1969.

${ }^{17}$ O'Byrne PM, Ryan G, Morris M, et al. Asthma induced by cold air and its relationship to nonspecific bronchial responsiveness to methacholine. Am Rev Respir Dis 1982;125:281-5.

${ }^{18}$ Menkes HA. Airway reactivity and the need for a simple test. Am Rev Respir Dis 1980;121:619-20.

${ }^{19}$ Chatham M, Bleecker E, Norman P, Smith PL, Mason P. A screening test for airways reactivity. An abbreviated methacholine inhalation challenge. Chest 1982;82:158.

${ }^{20}$ Cockcroft DW, Killian DN, Mellan JJA, Hargreave FE Bronchial reactivity to inhaled histamine: a method and clinical survey. Clin Allergy 1977;7:235-43.

${ }^{21}$ O'Cain CF, Dowling NB, Slutsky AS, et al. Airway effects of respiratory heat loss in normal subjects. J Appl Physiol 1980;49:875-80.

${ }^{22}$ Tattersfield A. Measurement of bronchial reactivity: a question of interpretation. Thorax 1981;36:561-5.

${ }^{23}$ Jarabek AM, Baker D, Gann PH et al. Cold air challenge in an occupational population exposed to platinum salts. Am Rev Respir Dis 1982;125:155. 